\title{
Notes on the vocalizations of Temminck's Lark (Eremophila bilopha) and Horned Lark (Eremophila alpestris)
}

\section{Peter Boesman}

In the following we briefly analyze and compare voice of the different races of Temminck's Lark (Eremophila bilopha) and Horned Lark (Eremophila alpestris). We also try to quantify the extent of any vocal differences using the criteria proposed by Tobias et al. (2010), as a support for taxonomic review. We have made use of sound recordings available on-line from Xeno Canto (XC) and Macaulay Library (ML).

Drovetski et al. (2014) distinguishes seven groups. We will start with Shore Lark, and then compare with the other groups by showing some typical sonograms:

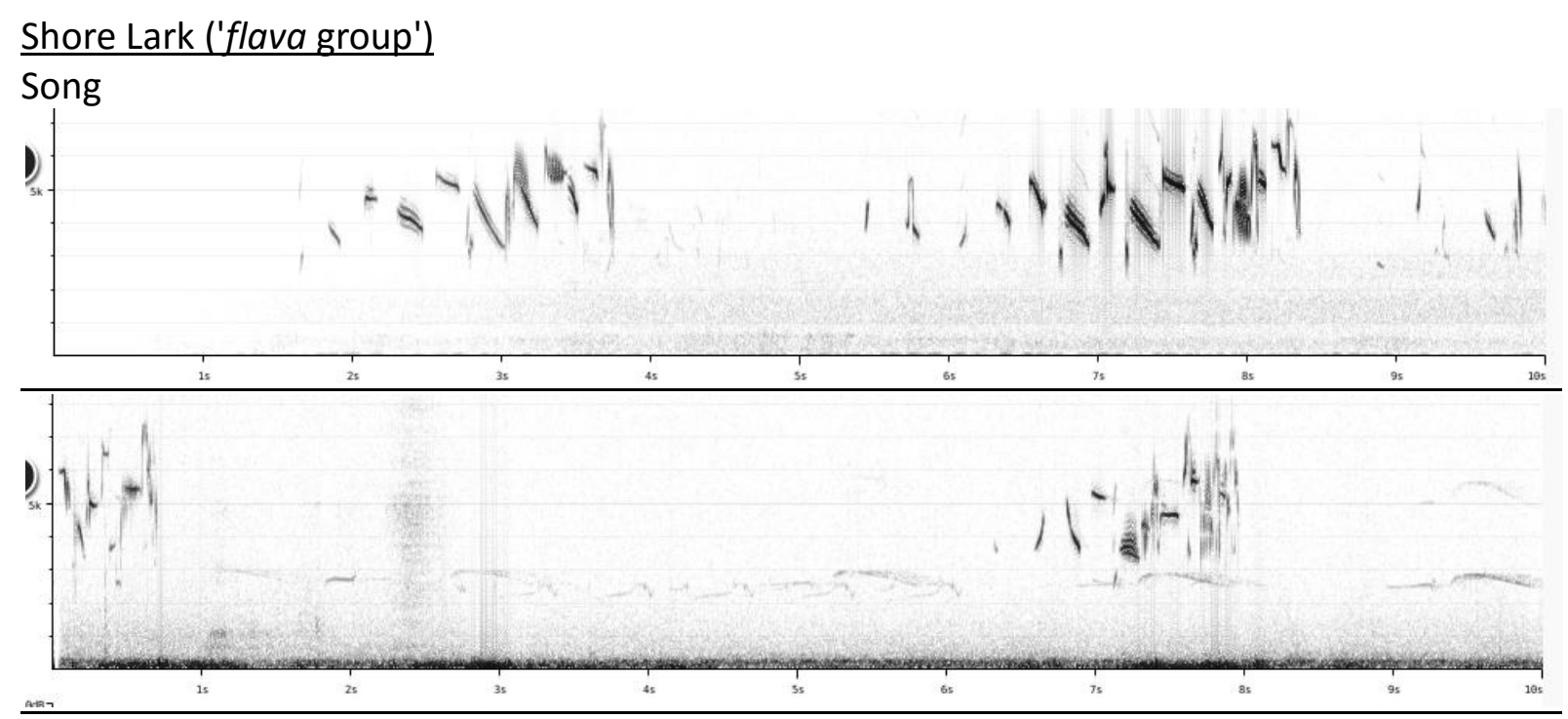

Calls

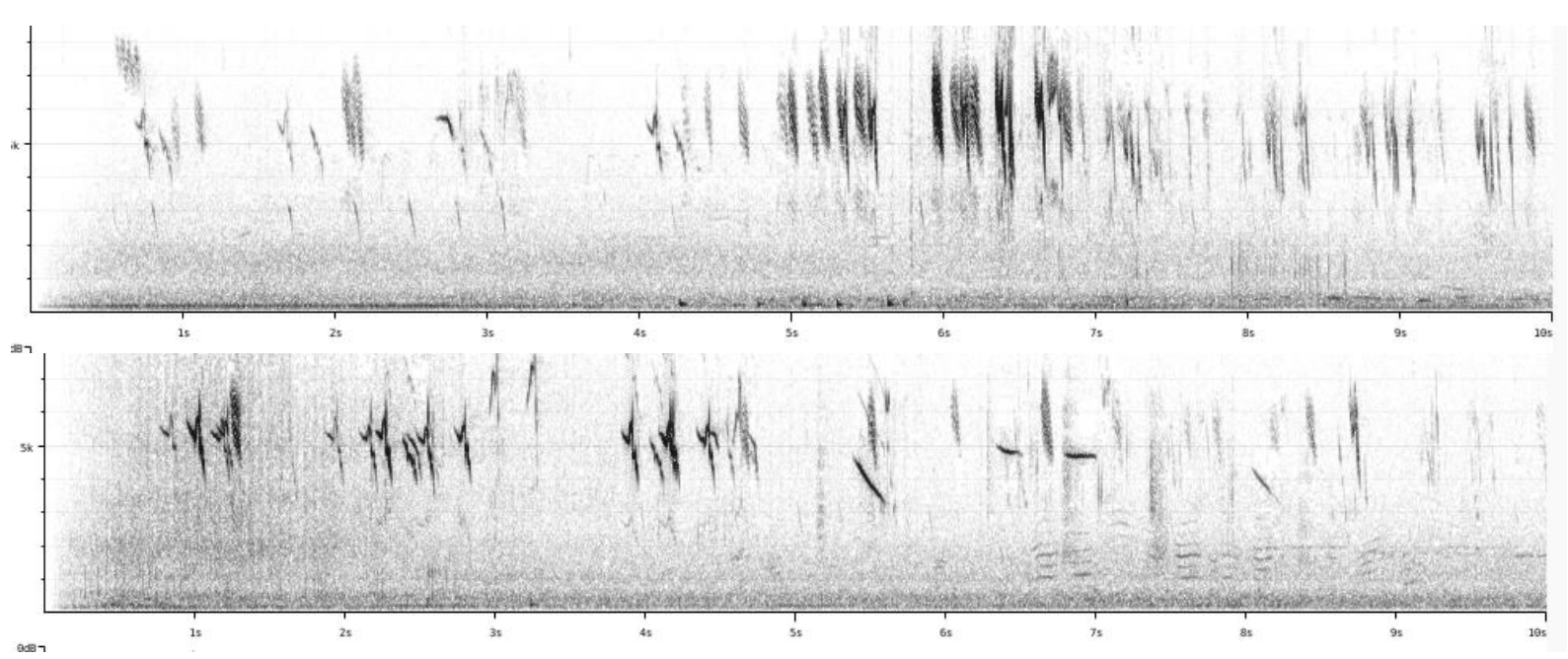


HANDBOOK OF THE

BIRDPIIUE WORLD ORNITHOLOGICAL NOTES

Atlas Horned Lark ('atlas group')

Song

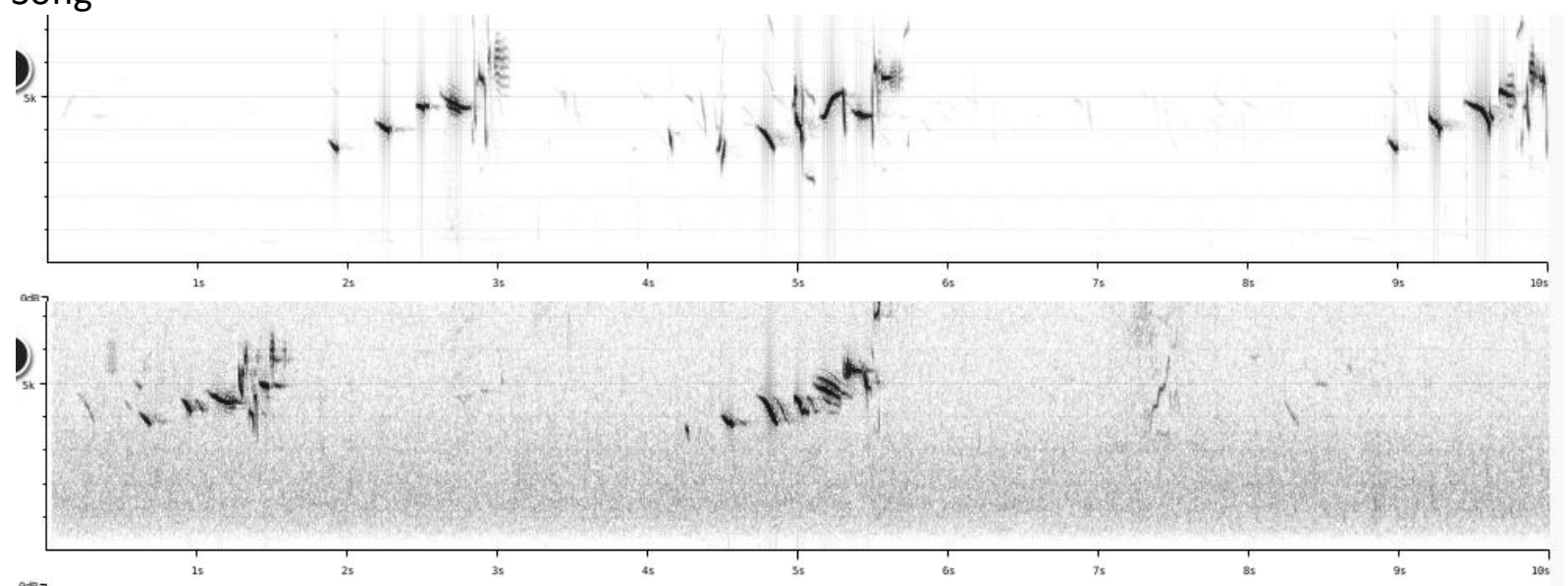

Calls
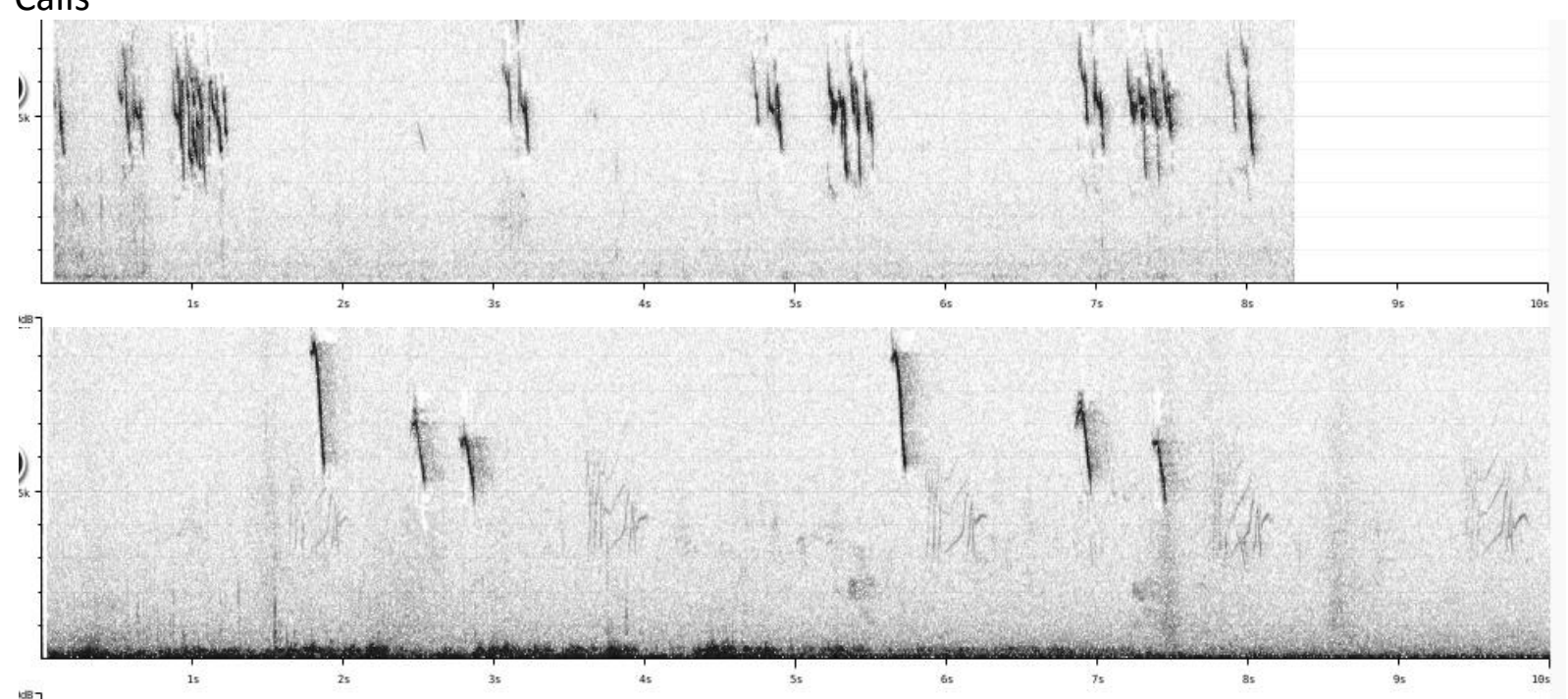

Both song and calls are quite similar to Shore Lark, but song apparently is more clearly rising (narrower frequency band in which notes vary in pitch) and 'slope' of notes less steeply downslurred.

Caucasian Horned Lark ('penicillate group')

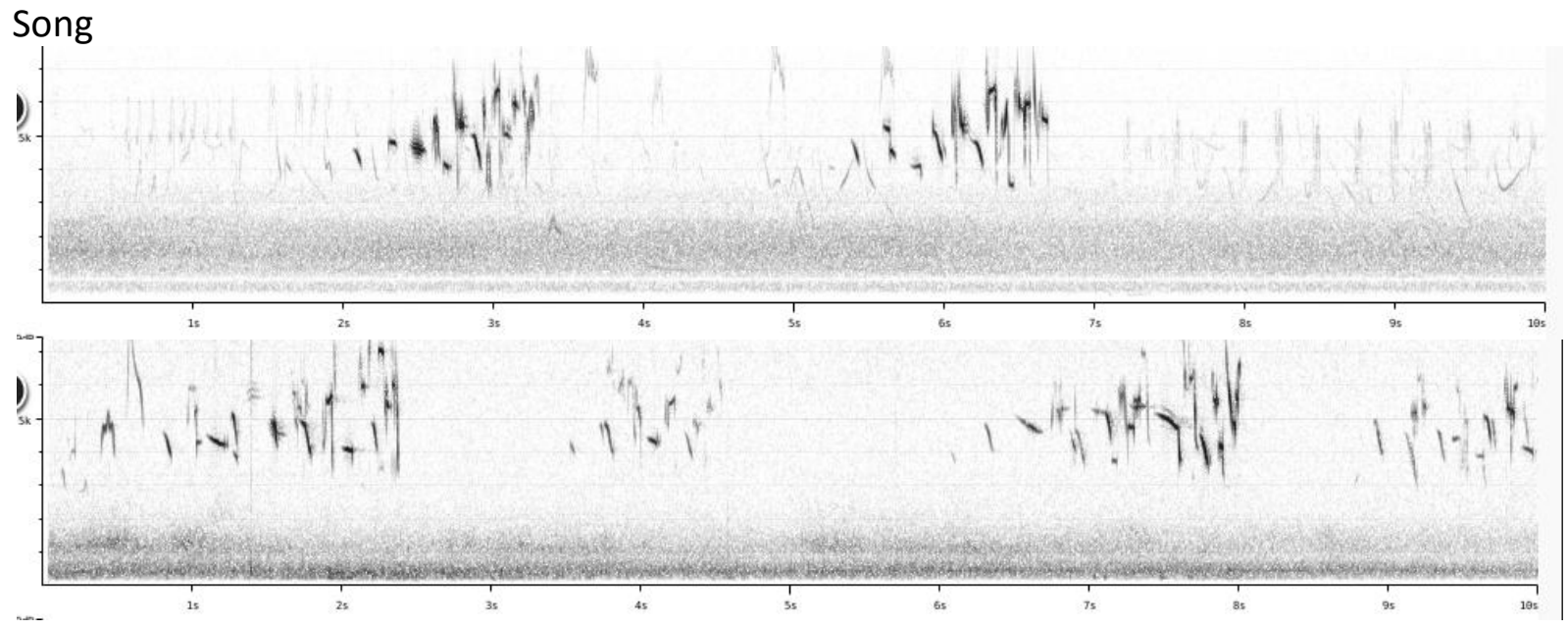

2 


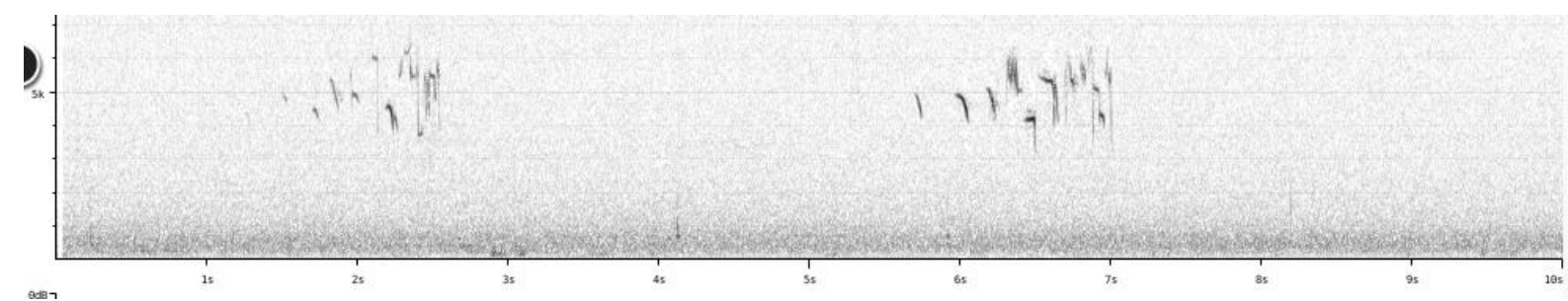

There seems to be no clear difference with Shore Lark. We haven't found good examples of true flight or alarm calls.

\section{Steppe Horned Lark ('brandti group')}

Song
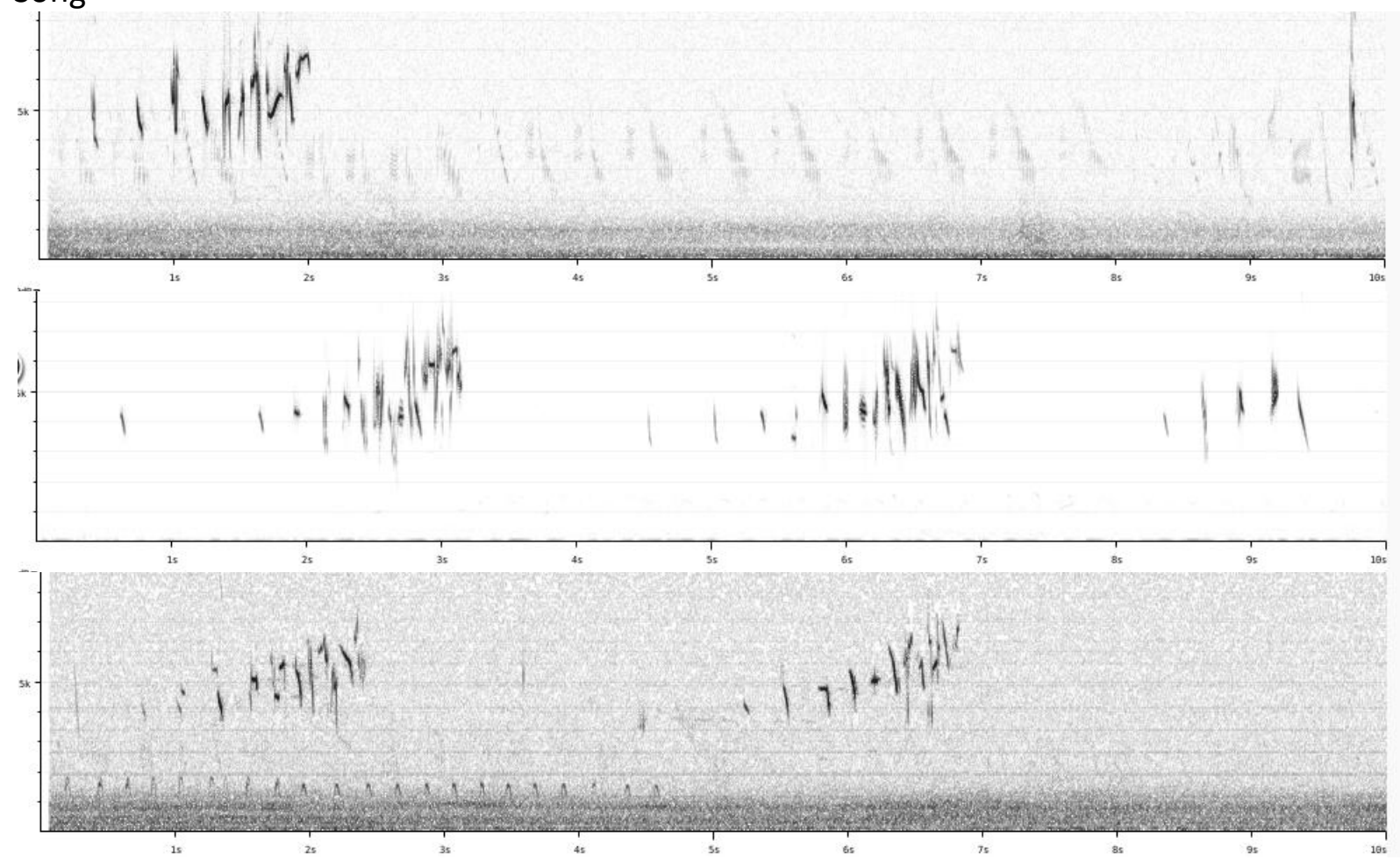

Call

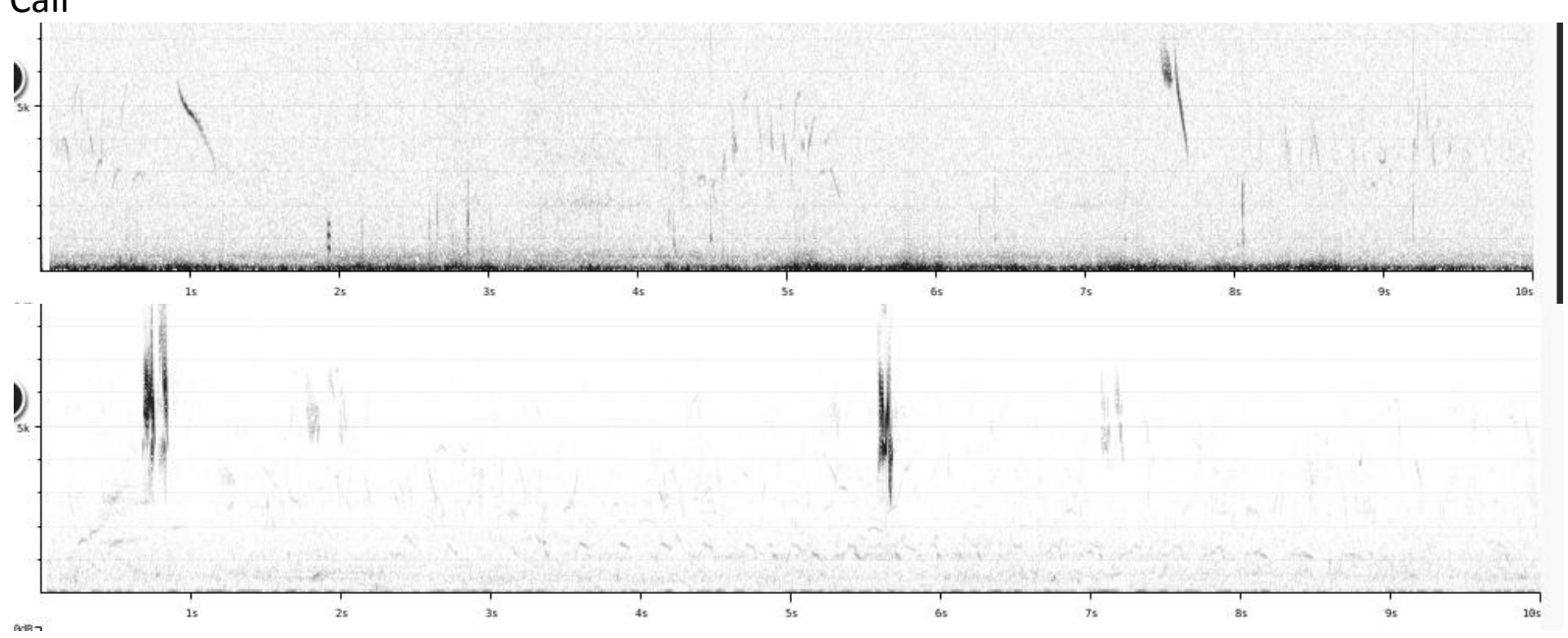


HANDBOOK OF THE

BIRDPPIVE WORLD ORNITHOLOGICAL NOTES

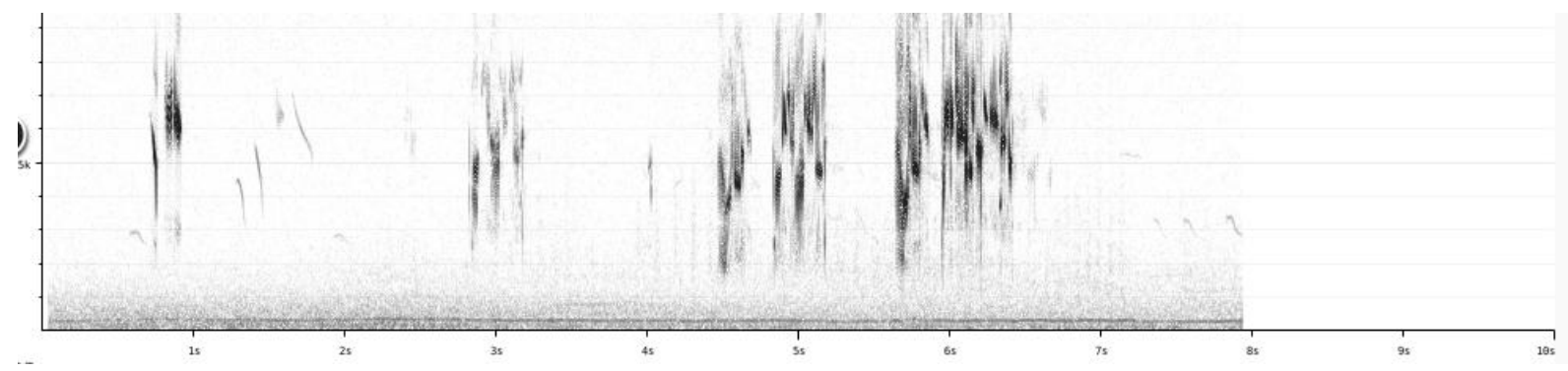

There seems to be little difference with Shore Lark. Notes in song possibly on average have steeper slope.

American Horned Lark ('alpestris group')

Song
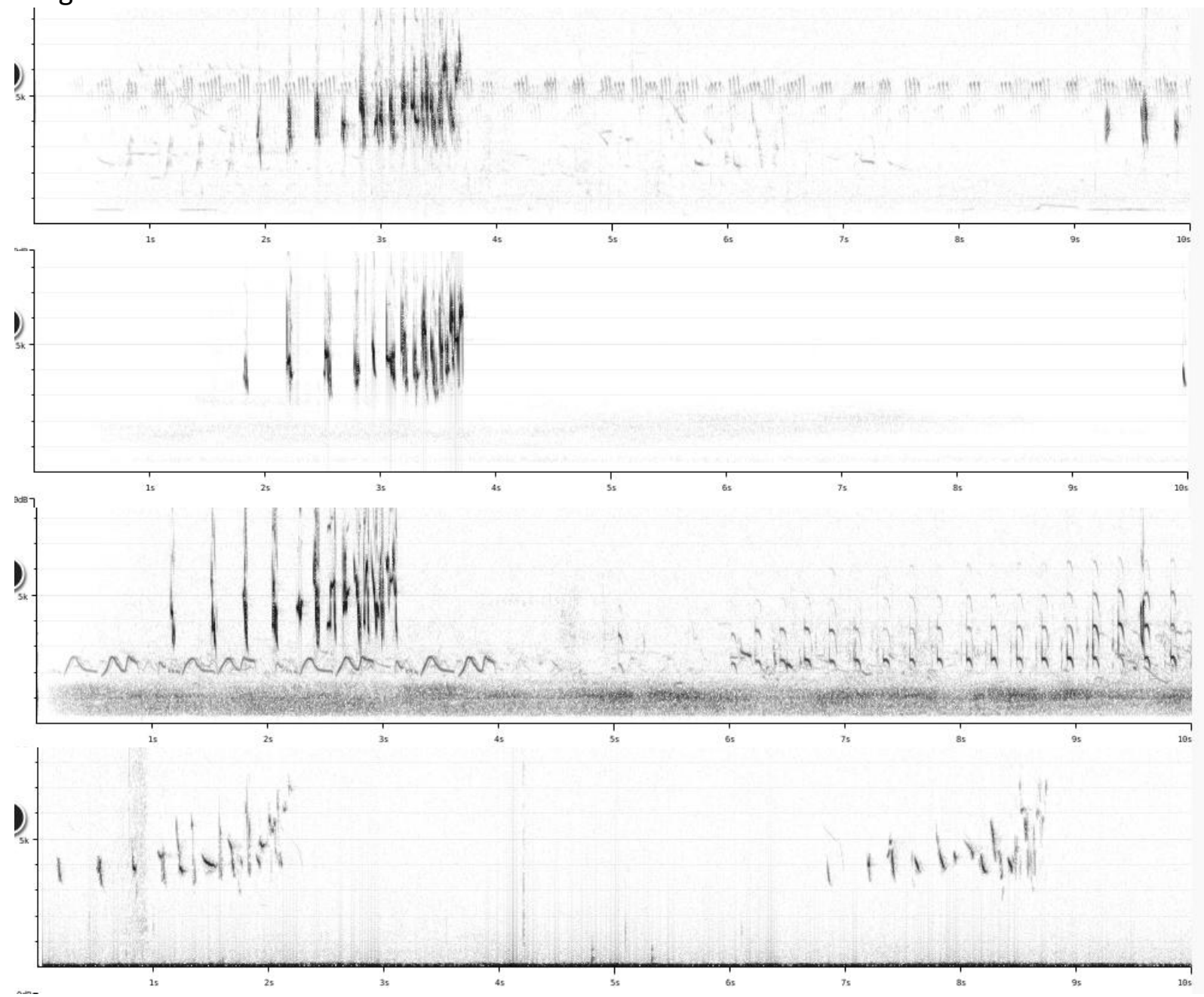

Call

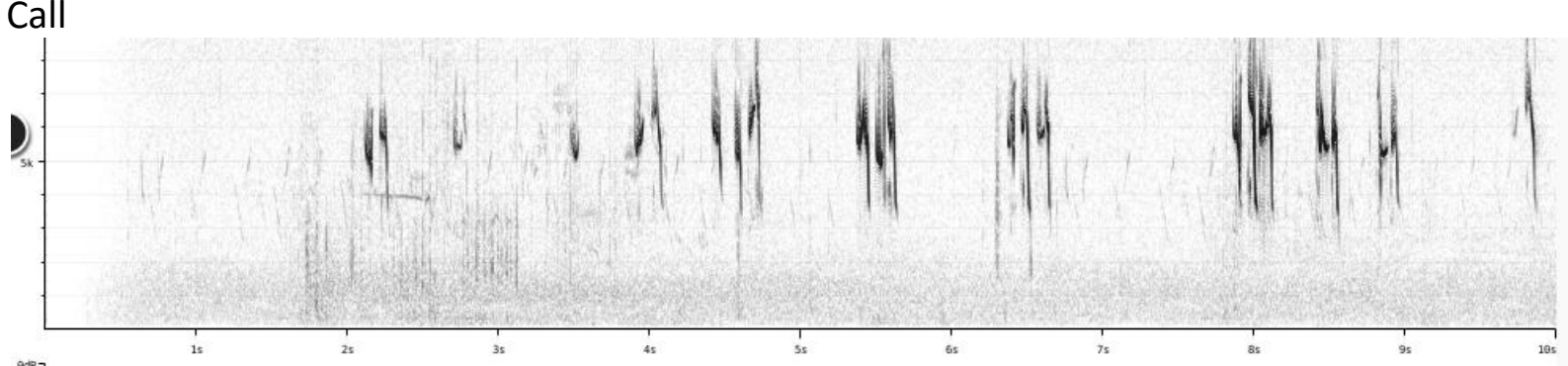

4 


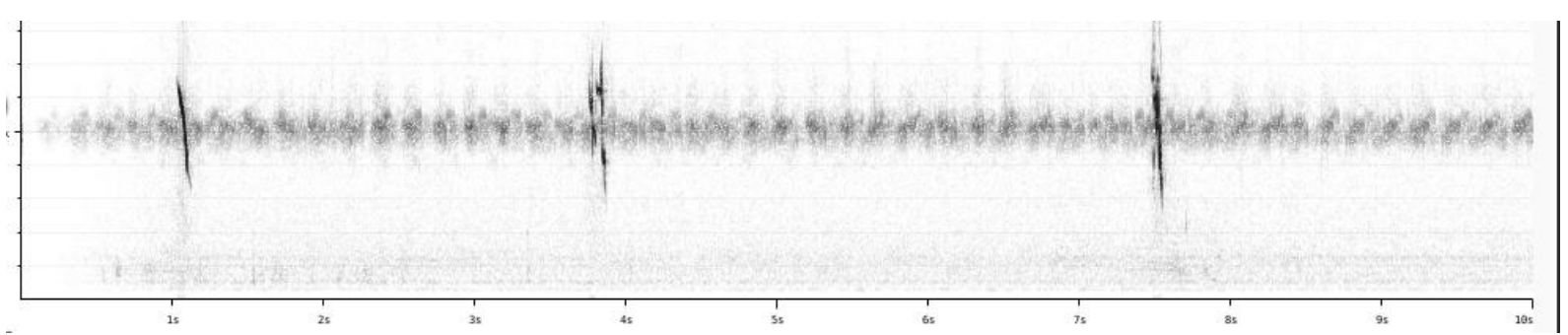

Song apparently lacks 'shallow-sloped' notes, nearly all notes being short and very steeply sloped. Calls rather similar to Shore Lark.

Himalayan Horned Lark ('elwesi group')

There are hardly any recordings of this group.

\section{Temminck's Lark ('bilopha group')}

\section{Song}
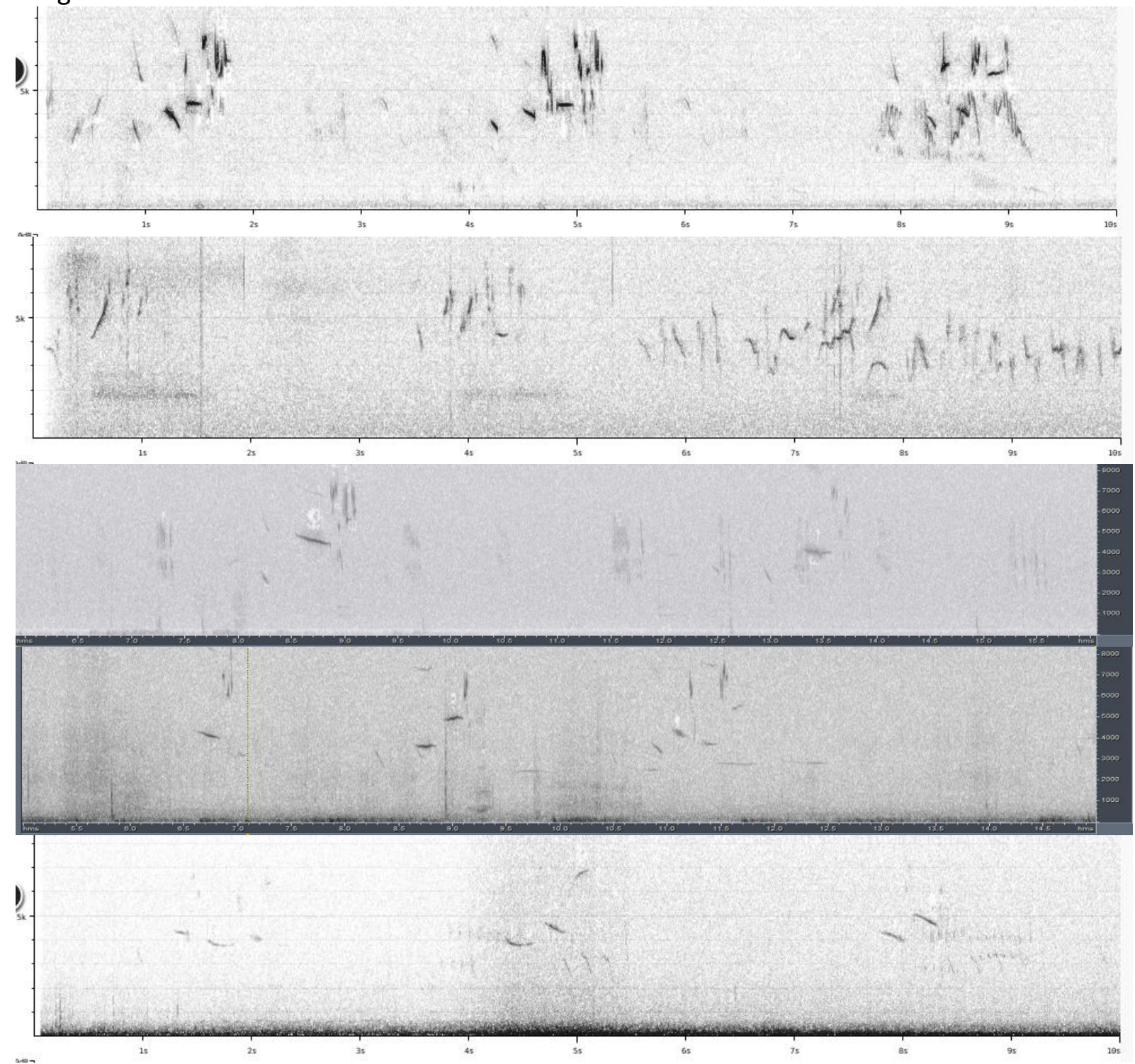

Call: no good examples found. 

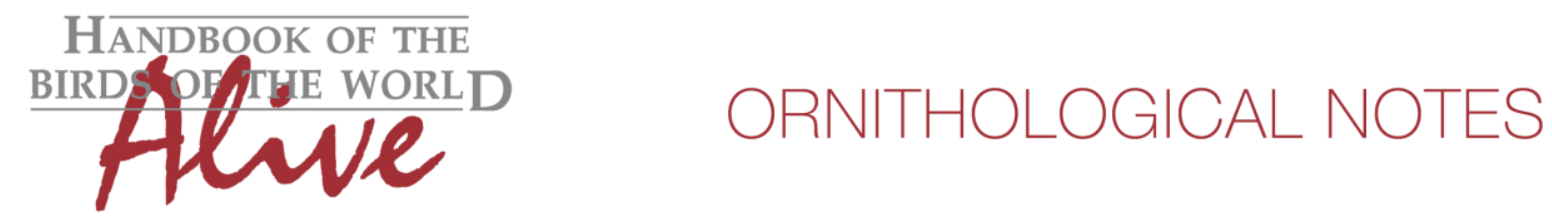

Song of Temminck's Lark in some cases quite similar to Shore Lark, but seemingly weaker, with less clearly built-up phrase, shorter and with less notes. In many cases however a very simple song, very unlike any of the above groups, consisting of just a few notes, of which first two rather flat in pitch (dee-dee-didi or similar).

Given that differences between many groups are at most very subtle, a thorough analysis with many samples would be needed to reach firm results.

At this point, we can say that the vocally most distinctive group is Temminck's Lark. No other group has such a different song. Based on the low number of notes in the song phrase (2), the seemingly low amplitude with which the song is delivered and the wide variation in song structure from extremely simple to fairly complex (1-2), a total vocal score of at least 3 could be given.

Of all the other groups, the one for which song would be identifiable in a blind test with reasonable confidence is Atlas Horned Lark, for its clearly rising song phrase due to the fairly narrow (rising) frequency band (hardly any notes covering a wide frequency range). Score 2.

American Horned Lark and Steppe Horned Lark are fairly close and share very steeply sloped notes, which could be given a score 1 vs Shore Lark and Caucasian Lark. (we haven't examined the many ML recordings of American Horned Lark to check robustness of this difference).

As already mentioned, we can't evaluate Himalayan Shore Lark due to lack of recordings.

This note was finalized on 8th February 2016, using sound recordings available on-line at that moment. We would like to thank in particular the many sound recordists who placed their recordings for this species on XC and ML.

\section{References}

Drovetski, S.V., Rakovic, M., Semenov, G., Fadeev, I.V. \& Red'kin, Y.A. (2014). Limited phylogeographic signal in sex-linked and autosomal loci despite geographically, ecologically, and phenotypically concordant structure of mtDNA variation in the Holarctic avian genus Eremophila. PLoS ONE 9(1): e87570.

Tobias, J.A., Seddon, N., Spottiswoode, C.N., Pilgrim, J.D., Fishpool, L.D.C. \& Collar, N.J. (2010). Quantitative criteria for species delimitation. Ibis 152(4): 724-746.

\section{Recommended citation}

Boesman, P. (2016). Notes on the vocalizations of Temminck's Lark (Eremophila bilopha) and Horned Lark (Eremophila alpestris). HBW Alive Ornithological Note 219. In: Handbook of the Birds of the World Alive. Lynx Edicions, Barcelona. (retrieved from http://www.hbw.com/node/932177 on 7 September 2016). 